\title{
MUJERES INDÍGENAS Y SISTEMA DE CARGOS EN EL SIGLO XXI. UN ACERCAMIENTO DESDE LA SIERRA DE ZONGOLICA, VERACRUZ, MÉXICO
}

\author{
INDIGENOUS WOMEN AND CARGO SYSTEM IN THE 21ST CENTURY. \\ AN APPROACH FROM SIERRA ZONGOLICA, VERACRUZ, MEXICO
}

\author{
María Teresa Rodríguez*
}

\begin{abstract}
En este artículo se realiza una aproximación diacrónica acerca de las especificidades del "sistema de cargos" en la región de Zongolica, área montañosa habitada por población indígena nahua, ubicada en la vertiente oriental de la sierra Madre, en el estado de Veracruz, México. Se subraya el impacto de la migración en las estructuras familiares y rituales y su correlato en el aumento de la participación femenina al frente de los cargos religiosos. El objetivo principal del texto es mostrar el papel de las mujeres nahuas en la esfera ritual y en la dinamización de las estructuras locales de la comunidad indígena transnacional en el siglo XXI.

Palabras claves: Sistemas de cargos, participación femenina, nahuas, migración.
\end{abstract}

This article presents an diachronic approach to the particularities in the cargo systemin the Zongolica region, a mountainous area inhabited by nahuas, located in the eastern portion of the Sierra Madre in the state of Veracruz, Mexico. The impact of migration in family and ritual structures is emphasised and so its correlation with the increase of women participation in high religious posts. The main objetive of this text is to show the role of nahua women in the ritual field and in the dynamization of local structures in the transnational nahua communities of the 21 st century.

Key words: Cargo system, women participation, nahuas, migration.

\section{Introducción}

El estudio de la relación entre la intensificación de los procesos migratorios en México y las transformaciones en prácticas, creencias y adscripciones religiosas, ha sido en los últimos lustros un campo fértil de investigación (Odgers, 2014). En las indagaciones acerca del impacto sociocultural de las migraciones transnacionales, se ha documentado que este tipo de movilidad va acompañada de nuevas formas de religiosidad vinculadas al envío de remesas, a la circulación y relocalización de imágenes y prácticas, a la celebración de festividades espejo en las zonas de recepción, a los procesos de conversión, y a la readecuación de estructuras rituales en las comunidades de origen (ver por ejemplo: Morán, 2000; Durand y Massey, 2001; Hernández Madrid, 2003; D' Aubeterre, 2005; Rivera-Sánchez, 2004; Sánchez Rivera 2006 y 2007; Hernández y Garma, 2007; Argyriadis, De la Torre, Gutiérrez Zúñiga y Aguilar Ros (coords.), 2008; Odgers y Ruiz, 2009;
Hirai, 2009; Juárez Cerdi, 2009; Jaimes Martínez, 2009; Fortuny, 2011; Rodríguez, 2011, entre otros).

El interés de este texto se inscribe en dicha línea de trabajo: explorar las prácticas religiosas en el contexto de las nuevas dinámicas de movilidad y espacialidad, subrayando los impactos de la migración transnacional en las localidades de origen, especialmente en relación con las estructuras familiares y rituales. Se enfatiza que el proceso migratorio tiene -entre otras derivaciones- su correlato en el aumento de la participación femenina en la esfera ritual. El objetivo específico del artículo es mostrar el papel de las mujeres nahuas en la dinamización del sistema de cargos religiosos en los pueblos serranos del siglo XXI.

Si bien es cierto que la migración de mexicanos hacia los Estados Unidos no es fenómeno nuevo, en determinados ámbitos regionales data apenas de lo que va de este siglo. Tal es el caso de algunas regiones veracruzanas -como la región de las Altas Montañas- $y$ especialmente de algunos municipios de la zona fría de la sierra de Zongolica, mismos

\footnotetext{
* Centro de Investigaciones y Estudios Superiores en Antropología Social (CIESAS-Golfo). Xalapa, México. Correo electrónico: mtrguez@ciesas.edu.mx
} 
que ahora sufren los efectos del declive de las agroindustrias cañera y cafetalera que proporcionaban empleo a jornaleros indígenas, si bien bajo condiciones sumamente precarias (Macip, 2005).

En estas páginas pretendo aportar algunas pistas etnográficas para el estudio de las repercusiones de la migración transnacional en la vida religiosa de los municipios nahuas serranos. En otro lugar mostré la relación entre la movilidad de trabajadores nahuas de Astacinga hacia los Estados Unidos y la diversificación religiosa, subrayando los vínculos entre dichos procesos migratorios y las estrategias de expansión de denominaciones evangélicas pentecostales (Rodríguez, 2011 y 2012). También he abordado el debilitamiento de determinados mecanismos de control social y la pluralidad religiosa, incluyendo la impronta de ciertas corrientes católicas como el Movimiento de Renovación Carismática y la Pastoral Indígena (Rodríguez, 2009).

Ahora me propongo poner atención especialmente a las transformaciones y continuidades de los sistemas de cargos religiosos, frente a las dinámicas de la movilidad transnacional en la sierra de Zongolica. Diversos trabajos han mostrado casos en que los sistemas de cargos han rebasado las fronteras mexicanas y las fiestas del calendario ritual se repite en ambos países, dando lugar a una nueva geografía de lo sagrado (Odgers, op. cit., 158). Sin embargo no existen aún suficientes evidencias etnográficas pertinentes a la región de estudio, por lo que estas notas pretenden realizar una modesta contribución en este campo. De acuerdo con Sassen (2012), el acercamiento antropológico a los estudios de las migraciones contemporáneas permite analizar las microestructuras de lo global y aportar datos respecto de algunos de los componentes subjetivos que entran en juego, así como acerca de las problemáticas más significativas para los migrantes, sus familias y sus comunidades de origen.

Aquí se plantea que la diversificación religiosa y el aumento en el volumen de migrantes hacia los Estados Unidos en determinados municipios han repercutido en la jerarquía de comisiones para las fiestas religiosas de culto a los santos. Es evidente un marcado dinamismo en relación con el ejercicio religioso -incluyendo la disidencia y adscripción a nuevos cultos-, así como las modificaciones de las estructuras ceremoniales que otorgan novedosos protagonismos a las mujeres y a las nuevas generaciones. Presentaré una aproximación a estas complementariedades recientes en el contexto contemporáneo de los habitantes de cuatro municipios nahuas veracruzanos: Atlahuilco, Astacinga, Texhuacan y Tlaquilpa ${ }^{1}$.

\section{Los cargos religiosos en la sierra de Zongolica en el siglo XXI}

El sistema de cargos en México y parte de Centroamérica, fue analizado durante un largo periodo como el centro de la vida comunitaria, desarrollándose distintas interpretaciones en relación con su funcionamiento y sus repercusiones en la organización social. Los primeros trabajos -en la primera mitad del siglo veinte- se orientaron hacia la relación entre este tipo de organización y sus vínculos con las formas de acceder al poder y de normatividad social y económica. El sistema de cargos se homologó con la categoría de comunidad. La comunidad se entendía como el conjunto de unidades territoriales que conforman un municipio: en cada municipio existía una jerarquía de cargos seculares y una jerarquía paralela de funcionarios religiosos; los espacios municipales constituían las divisiones étnicas básicas (Sol Tax,1937).

A partir de entonces se sistematizó dicha jerarquía cívico-religiosa y se analizó como la esencia de la comunidad indígena. A escala local, esta jerarquía representaba un mecanismo para "tabular" el consenso en torno a asuntos de diversa índole y para normar los relevos generacionales y la sucesión en los cargos civiles y políticos. Se apuntó también, aunque de manera más bien marginal, su vertiente religiosa orientada hacia el aspecto devocional, es decir, las subjetividades implícitas en esta relación con las divinidades. Mediante el sistema de cargos se aseguraba la celebración oportuna y precisa de las fiestas del calendario religioso y se recibía a cambio protección divina y beneficios materiales.

Estos postulados darían pie a una cascada de estudios muy diversos a lo largo de varias décadas, la mayoría de ellos muy interesantes y propositivos. Eric Wolf [1967] (1986), por ejemplo, sostuvo que el sistema de cargos cívico-religiosos tenía efectos niveladores, ya que funcionaba como un freno hacia la distinción de clases, mantenía una homogeneidad social y constituía el canal más aceptable para el desempeño personal. Aguirre Beltrán (1991), al retomar los planteamientos de algunos de sus antecesores, asignó al sistema de cargos funciones eminentemente integrativas que 
sustentaban la cohesión del grupo y restringían los contactos hacia fuera. Aguirre Beltrán (1991) también interpretó a los sistemas de cargos como la institucionalización del derroche, mecanismo de control social que impedía la acumulación de unas familias sobre otras y al mismo tiempo proporcionaba prestigio al hacer ostensible la riqueza.

En la forma clásica de este sistema (véase Chance y Taylor, 1987) se trataba de una escala de cargos anuales, en la que todos los hombres de la comunidad tenían la oportunidad de ascender a los escalones superiores participando alternadamente en los cargos civiles y los religiosos, hasta llegar a los puestos más altos de cada una de las esferas (mayordomo del santo patrono y presidente municipal). Posteriores y numerosos trabajos-imposibles de citar en este espacio (cfr. Korsbek, 1996)-ilustrarían respecto de una diversidad de modalidades de los sistemas de cargos en una variedad de situaciones etnográficas. Basados en esta amplia documentación, surgió el acuerdo de que la hipótesis de la nivelación económica no era demostrable, pero que una estratificación significativa tampoco era compatible con el sistema (Chance y Taylor, ibídem).

Cancian (1976) se preguntó, por ejemplo, concerniente a la evolución del sistema de cargos en Zincantan, municipio tzotzil de los Altos de Chiapas. Argumentó que a medida que el crecimiento demográfico fuera compensado con la creación de nuevos cargos, continuarían las consecuencias integradoras del sistema en favor del equilibrio en la comunidad. Cancian, como otros autores, consideraba que el enriquecimiento individual representaba una amenaza para el equilibrio de la comunidad. Varios lustros después el propio Cancian (1990) hubo de reconocer que el sistema de cargos de Zinacantan sufrió un desplazamiento como institución central y dominante de la estructura social, debido a la diversidad ocupacional entre sus habitantes y a los cambios en las relaciones entre los parajes y la cabecera municipal. Bricker (1989) y Wasserstrom (1989) registraron el surgimiento de un etnocentrismo expresado a nivel del caserío mediante la construcción de capillas, oficinas administrativas y cárceles, en un esfuerzo de sus habitantes por depender cada vez menos del Ayuntamiento y de las iglesias ubicadas en el centro ceremonial. Los cargos religiosos y las ceremonias de renovación de año ya no resolvían las nuevas divisiones sociales y los conflictos políticos.
Si bien los análisis de estos y otros autores fueron muy acertados, llama la atención que ninguno de ellos haya considerado el factor del pluralismo religioso como un fenómeno de complicadas derivaciones en los Altos de Chiapas. Habría que esperar unos años para ver los resultados de importantes trabajos orientados a esta temática, cuyas contribuciones han aportado datos para la comprensión del conflicto religioso, tanto en los Altos de Chiapas como en otras regiones de México y Guatemala (por ejemplo: Garma, 1998; Rivera, 1998, 2001, 2003; García, 1993, 1996; Robledo, 1997, 1998; Cantón, 1998, entre otros).

Las profundas transformaciones de las localidades indígenas a lo largo de las últimas décadas impiden hablar de la vigencia de los sistemas de cargos cívicos y religiosos como sistemas unificados, quizás salvo raras excepciones. Para Chance (1990), el divorcio entre ambas esferas fue el cambio estructural más relevante hacia fines del siglo veinte. Este cambio implicó su orientación hacia organizaciones más abiertas y más centradas en los aspectos rituales y devocionales. Al mismo tiempo quedó atrás la idea de la comunidad estable y homogénea como campo conceptual, y el sistema de cargos como mecanismo estabilizador. Veamos rápidamente qué ha ocurrido en la sierra de Zongolica².

Es difícil precisar el contexto espacio-temporal del surgimiento de los sistemas de cargos religiosos en la sierra de Zongolica, ya que no se cuenta con archivos parroquiales ni otras fuentes primarias. Sin embargo, es probable que haya emergido hacia mediados del siglo XIX, de acuerdo con la propuesta planteada por Chance y Taylor (1987) para otras áreas de México, aun cuando se fue gestando desde los primeros tiempos de la Colonia. Como ha señalado Báez-Jorge (1998), la institucionalización de modelos de autogestión laica para el ejercicio de la religiosidad fue una de las respuestas adaptativas de la población colonizada, para estrechar los lazos de solidaridad étnica frente a la imposición y el dominio colonial. Estos procesos implicaron también la yuxtaposición de interpretaciones y prácticas que aún hoy expresan la vitalidad de conceptos y creencias vinculados a la tradición religiosa mesoamericana.

La noción de tradición religiosa mesoamericana (López Austin, 1994) ha sido de gran utilidad para dar cuenta del complejo religioso en el que quedaron incluidas las prácticas y creencias de las distintas 
sociedades de agricultores mesoamericanos, sumadas a las prácticas producidas por el proceso de evangelización católica. Esta noción ha sido sin duda un aporte sustancial para el estudio de las religiosidades indígenas y para la comprensión de los procesos históricos de una dilatada extensión de nuestro país. Sin embargo, es urgente advertir el surgimiento de nuevos hibridismos y formas de organización que permean la ritualidad indígena y que nos plantean nuevos retos teóricos y metodológicos.

Es preciso observar los distintos modelos de coexistencia entre los sistemas de cargos religiosos aún muy vitales en los pueblos de la sierra -que implican la rotación de los puestos de mayordomía y el esplendor de las fiestas patronales-y las novedosas propuestas religiosas procedentes tanto del seno mismo de la Iglesia católica, como de Iglesias evangélicas, sobre todo de orientación pentecostal. Garma (1987) registró en Ixtepec, un pueblo totonaco de la sierra norte de Puebla, México, que los pastores protestantes se convirtieron al "evangelio" al estar fuera de la comunidad, tras el contacto con "hermanos" en los lugares en los que permanecieron un tiempo por motivos laborales.

Desde la segunda mitad del siglo veinte han tenido presencia en la sierra diversas iglesias evangélicas. Sobresale La Luz del Mundo, con sus vistosos y llamativos templos, pero también existen otras iglesias pentecostales y neopentecostales de menor visibilidad en el paisaje, pero no por ello menos importantes. Como ha señalado Garma (2004), el pentecostalismo en las regiones indígenas se apoya en figuras carismáticas y tiene en la sanación por la fe un poderoso instrumento para lograr conversiones. En la sierra aún predominan los católicos de forma indiscutible; solo en contados municipios la cantidad de conversos es significativa, llegando incluso a representar a un tercio de la población, como es el caso de Astacinga ${ }^{3}$. No obstante, en la mayor parte de los municipios los cargos ceremoniales y fiestas de mayordomía siguen jugando un papel destacado, tanto en el espacio público como en los ámbitos privados donde se desarrollan la mayoría de las secuencias ceremoniales.

En algunos pueblos de la sierra se manifiesta preocupación entre los cargueros en relación con los procesos relacionados con la migración transnacional y frente a las presiones de carácter económico, así como de cara a la proliferación de las distintas denominaciones religiosas; se trata de sectores tradicionalistas que apelan a la ratificación de "las costumbres" que les transmitieron los abuelos. Les preocupa el proceso lento pero firme que implica la disminución de la participación de los jefes de familia en los cargos ceremoniales.

Según mi propia observación, hasta la década de los años ochenta, en distintas localidades de la sierra las autoridades civiles aún intervenían en la asignación de los cargos religiosos; se encontraban vigentes distintas formas de coerción para que la persona elegida aceptara el puesto de mayordomo, aun contra su voluntad. Sin embargo, es difícil afirmar que en algún momento constituyó un sistema alternante entre los cargos cívicos y religiosos en el que todos los hombres adultos debían participar. Como quiera que haya sido, hoy no hay evidencias de la vigencia de una relación directa entre participación en el sistema de cargos religiosos y el ascenso político. Antes bien, en los últimos lustros, los presidentes de algunos municipios de la sierra han sido profesos de denominaciones evangélicas.

De manera análoga a lo señalado por Dow (1993) para el caso de Santa Mónica -un pueblo otomí del estado de Hidalgo, México- en la sierra de Zongolica, los valores del capitalismo adquiridos por el trabajo migratorio transnacional entraron en contradicción con las ideas redistributivas del sistema de cargos; muchas personas expresan que es mejor gastar en la construcción de una casa de mampostería que en una fiesta religiosa. Una muestra de este rechazo es la expansión del protestantismo en determinados pueblos, así como de los grupos católicos que también se oponen a los gastos suntuarios del sistema de cargos.

A partir de lo que va del siglo XXI, el panorama social y cultural de los pueblos serranos ha dado un giro de ciento ochenta grados. La emigración hacia los Estados Unidos se convirtió en una opción para los hombres jóvenes y de mediana edad -y todavía para pocas mujeres- de los municipios de la parte alta de la sierra en busca de empleos mejor remunerados. Si bien la emigración estacional hacia las plantaciones de las tierras bajas y las planicies costeras es un fenómeno de antiguo cuño, recientemente se incorporó la modalidad de la migración internacional como un fenómeno común en un número creciente de localidades serranas. Este movimiento genera cambios inéditos en la forma de vida de los pueblos nahuas que es preciso documentar. Dichos cambios se relacionan con la incorporación de hábitos y formas de pensamiento emancipadas de las restricciones territoriales. 
La libertad de movimiento hacia afuera de la región o del país se ha convertido en un nuevo factor de estratificación en la medida en que aporta un valor a la capacidad de consumo individual (Bauman, 2001). De ahí que la participación suntuaria en el sistema de cargos religiosos ha sido desplazada como la fuente más importante de adquisición de prestigio social. Asimismo, la diversificación religiosa otorga mecanismos para la socialización en esferas más localizadas y delimitadas. Por otra parte, las capillas instaladas en las congregaciones tienden a ganar autonomía del sistema ceremonial centralizado en la cabecera municipal, aun cuando se reproducen con vitalidad las fiestas patronales cuyo carácter es también secular y continúan como símbolo de adscripción y pertenencia.

En la dinámica de expansión de las nuevas denominaciones religiosas, el rechazo al consumo de alcohol es el argumento más esgrimido por parte de los conversos, así como por los pastores e incluso por determinadas corrientes católicas como el Movimiento de Renovación Carismática, presente en varios municipios de la zona. Quizás por ello en algunas localidades los mayordomos y otros funcionarios religiosos han ido abreviando los procedimientos ceremoniales y han flexibilizado los requisitos de participación -entre ellos la injerencia femenina más visible- mostrando apertura y capacidad de adaptación a los nuevos tiempos.

\section{Participación femenina en el ejercicio religioso}

Como señala Clifford (1999), el funcionamiento en redes transnacionales puede generar una nueva relación con el lugar de origen y fundar un sentimiento de pertenencia o una experiencia de identidad que no se encuentra estrictamente ligada al anclaje territorial. Si bien estoy de acuerdo con estos planteamientos, en este apartado me propongo argumentar que la migración transnacional en la zona de estudio, que implica la ausencia de varones, genera su distanciamiento -no solo físico sino también material y simbólico- de los cargos ceremoniales en sus lugares de origen.

A diferencia de lo que ocurre en otros contextos indígenas, los migrantes de la sierra (de los municipios referidos) son partícipes de otras formas de control social y adquisición de prestigio, diferentes a las derivadas de la participación en los cargos religiosos. La migración transnacional ha dado lugar a la modificación de ciertas reglas de convivencia; los jóvenes migrantes se encuentran mucho menos atados a las jerarquías emanadas de las obligaciones rituales tradicionales, como las relaciones de parentesco ritual y las fiestas de mayordomía dedicadas a las imágenes de los santos (Rodríguez, 2014: 70). Desde hace años, las ganancias obtenidas de la migración interna -hacia las plantaciones de caña y café de la bocasierrase destinaban en parte al financiamiento de los compromisos ceremoniales relacionados con los sistemas de compadrazgo y de fiestas religiosas. Sin embargo, hoy la experiencia migratoria transnacional no siempre deriva en el fortalecimiento o continuidad de las esferas tradicionales. Antes bien, conduce a una redefinición de valores, expectativas y horizontes culturales.

En esta redefinición encontramos un cambio también en la jerarquización de hombres y mujeres. De forma parecida a la descrita por Marisol De la Cadena (1992) para el Cuzco, en nuestra zona de estudio las subordinaciones de género se manifestaban de manera indiscutible en las relaciones patriarcales, partiendo de nociones de superioridad e inferioridad legitimadas por diferencias de género. Ello implicaba que las mujeres estuvieran descalificadas para acceder a las fuentes de poder. Sin embargo, frente a la ausencia prolongada de cónyuges, padres o hermanos debido al trabajo migratorio transnacional -así como a la educación escolarizada y el internet, entre otros factores-, se encuentran en redefinición las relaciones de género y la estructura patriarcal empieza a verse amenazada.

La conyugalidad a distancia ${ }^{4}$ se mantiene mediante el envío de remesas para la construcción de una vivienda -principal objetivo del trabajo migratorio- y para los gastos de manutención del grupo doméstico. Sin embargo, pareciera que la gestión de los puestos de mayordomía no es un tema de interés para los hombres migrantes, en tanto no pueden estar presentes en el proceso ritual. Este fenómeno deja espacios vacíos en los puestos del calendario ceremonial, dando paso a la gestión de las personas que se quedan en las localidades serranas, y posibilitando la participación de mujeres solteras, separadas o viudas.

La transformación de las formas de transmisión ritual y de autoridad en la sierra de Zongolica es una de los consecuencias coyunturales más relevantes de la movilidad transnacional, ya que 
dio lugar a un tránsito en los roles de género en el ámbito ceremonial. También ha ofrecido a los jóvenes migrantes mayor capacidad de agencia para distanciarse de la matriz dada de posiciones sociales, quienes tienden a cuestionar el excesivo ritualismo y las obligaciones asociadas a ello. No obstante, a pesar de las evidencias etnográficas con que cuento hasta ahora, es difícil llegar a conclusiones totalizadoras, ya que las respuestas son diversas en los distintos contextos espacio-temporales. Por ejemplo, Martínez Canales (2010) señala que en Tehuipango -municipio ubicado en la misma zona de estudio- los migrantes continúan con la colaboración pecuniaria para el levantamiento de capillas y para la compra de flores y otros elementos de la parafernalia religiosa.

Sin embargo, funcionarios religiosos de Astacinga, Atlahuilco, Tlaquilpa y Texhuacan refieren su preocupación por el incremento del número de puestos vacantes para la celebración de las festividades religiosas a partir de la migración, pues las remesas raramente se destinan a este rubro. Es sin duda el carácter transnacional del fenómeno migratorio lo que está dando lugar a estos cambios. Los pueblos nahuas de la sierra de Zongolica tienen una antigua tradición migratoria hacia los campos de cultivo de caña y café en la franja central veracruzana, así como a otros nichos laborales en las zonas urbanas regionales y hacia el área metropolitana de la ciudad de México. Sin embargo, ello no les impedía patrocinar las fiestas y estar presentes durante la gestión de su cargo. Antes bien, el trabajo migratorio constituía, en gran medida, el sostén de vida ceremonial, como lo dilucidó Aguirre Beltrán a mediados del siglo veinte, cuando las Regiones de Refugio se caracterizaban por un tipo de movilidad estacional o pendular (Aguirre Beltrán, 1991).

Como consecuencia, hoy las mujeres han adquirido responsabilidades diversas en el sostenimiento del ciclo ceremonial. Por ejemplo en Atlahuilco una mujer ocupa el cargo de Presidente Eclesiástico-funcionario responsable de coordinar a los mayordomos y de supervisar el desarrollo de cada una de las fiestas del calendario ritual-. Este puesto había sido de exclusividad masculina, elegido por consenso de entre el grupo de cargueros, mayordomos en turno y ancianos principales que pasaron por distintos cargos a lo largo de su vida. De acuerdo con mis informaciones, en este caso el párroco tuvo la última palabra y eligió para el puesto a una persona de su confianza, una madre de familia asidua a las actividades de la iglesia, no obstante el desacuerdo de parte de los pobladores, acostumbrados a un tipo de organización encabezada por varones.

Los habitantes de Atlahuilco -con excepción de los conversos a iglesias evangélicas- han adoptado ciertos cambios exitosos para la vitalidad y mantenimiento del sistema de cargos religiosos, dando paso a la participación de hombres y mujeres de cualquier edad, estado civil y condición social. Las mujeres jóvenes participan en la catequesis, en el coro, así como en retiros y encuentros juveniles organizados por el párroco, sin dejar a un lado su asistencia y responsabilidades en las fiestas de mayordomía. No resulta para nada extraño que acepten o soliciten un cargo como mayordomas, haciendo patente su solvencia económica y moral aun cuando no tengan esposo. En este lugar tuve ocasión de asistir a una fiesta de mayordomía cuya responsabilidad recaía en una joven soltera. Aunque contó con el respaldo de su padre y sus parientes, ella fue quien asumió la responsabilidad moral y social que implicaba el cargo, con la mayor seriedad y compromiso.

En Astacinga he podido constatar que las mujeres juegan un papel fundamental para el mantenimiento y continuidad del ciclo anual de festividades religiosas. Este municipio sobresale a escala regional por el incremento paulatino de la población migrante, especialmente entre las generaciones jóvenes. No obstante, mientras que los varones eligen destinos transnacionales, las mujeres se encaminan hacia el norte del país, especialmente a la ciudad de Monterrey, Nuevo León, donde son empleadas como trabajadoras domésticas 5 .

Durante las misas dominicales celebradas en la cabecera municipal se aprecia con claridad el predominio de la presencia femenina sobre un reducido grupo de hombres mayores. En este lugar ha cobrado fuerza el Movimiento de Renovación Carismática, impulsado por el párroco ante la impronta de las denominaciones pentecostales que han ganado numerosos adeptos a lo largo y ancho del municipio.

Durante mi estancia en la cabecera municipal de Astacinga en agosto de 2012 para asistir a la celebración de la fiesta patronal en honor a la Virgen de la Asunción, observé la presencia de mujeres migrantes que regresaban al pueblo para participar en la fiesta. Ataviadas con prendas de corte citadino, regresaban para rendir culto a la Virgen y para cumplir compromisos relacionados con el parentesco ritual en bautizos y casamientos que se 
celebraron de manera colectiva en aquella ocasión. A diferencia de los hombres migrantes que se encuentran en Estados Unidos, ellas pueden regresar eventualmente al pueblo para visitar a sus familiares y hacer frente a sus responsabilidades de diversa índole. En este contexto, mantuve una conversación con dos hermanas que llegaron desde Monterrey, donde trabajan como empleadas domésticas al igual que otras paisanas del mismo municipio. $\mathrm{Me}$ informaron que al año siguiente se harían cargo de celebrar la mayordomía en honor a San José, en la que invertirían sus ahorros de varios años de trabajo. Me transmitieron su ilusión en la realización de esta fiesta a la manera tradicional, ya que -según sus propias palabras-en Astacinga se han dejado de lado muchas celebraciones del calendario ritual, ante la ausencia de personas dispuestas a asumir el compromiso de celebrar una mayordomía. Los varones "ya no quieren el compromiso porque ahora tienen otros gustos, ya no quieren seguir la costumbre". La ausencia de candidatos varones para cubrir los cargos en Astacinga también ha abierto las puertas a la participación femenina, independientemente de su edad y estado civil.

Este proceso contrasta de manera clara con lo que plantea Rodríguez Blanco (2011) para el caso de Cuetzalan, Puebla. Según esta autora, generalmente las mujeres ocupan cargos religiosos a partir de los 60 años y cuentan con hijos que las respalden económicamente. Pero en el caso que nos ocupa, las mujeres -migrantes o no- tienen un papel activo en el nuevo escenario de la comunidad transnacional ${ }^{6}$. Demuestran su capacidad para sostenerse económicamente y para tomar decisiones de manera autónoma, ante el distanciamiento masculino de las obligaciones rituales y frente a los vacíos favorecidos también por la expansión de las denominaciones pentecostales en este municipio.

En Texhuacan es frecuente, de igual manera, que las mujeres asuman sobre sus espaldas la responsabilidad que implica el desempeño de un cargo como mayordomas. Es el caso de doña Paula, cuyo esposo se encuentra en prisión desde hace varios años. Permanecen con ella dos hijos aún menores de edad a quienes debe mantener por cuenta propia realizando diversas tareas: trabajo doméstico, crianza de animales de traspatio, venta de leña y productos de la milpa, entre otras. Aun en estas condiciones, solicitó la mayordomía de la Virgen de Guadalupe en diciembre de 2012, respaldada por sus vecinos y parientes así como por su profunda devoción a "la virgencita".

El ejercicio femenino de los cargos también está relacionado con la posibilidad de adquirir prestigio y reconocimiento social. Mujeres como doña Paula se apropian de los símbolos del prestigio masculino asociado a la jefatura del hogar como una vía para obtener visibilidad y aceptación social. Estos símbolos, apuntalados por la fe y las creencias religiosas, se despliegan en la escena pública sin la necesaria participación de un cónyuge.

Este tipo de situaciones se repite en distintos pueblos de la sierra y hacen explícito y evidente el proceso de superación de la exclusión de las mujeres a los roles protagónicos en la esfera ritual. Además, las mujeres también están accediendo a puestos del gobierno civil, antes de absoluta exclusividad masculina. Mujeres indígenas han sido presidentas municipales en Astacinga, Los Reyes, Tlaquilpa y Zongolica durante la última década. También ha habido diputadas y regidoras, aunque siguen siendo infrarrepresentadas en los puestos políticos como en casi todas partes del país y del mundo. Desde mi punto de vista, los niveles de educación escolarizada y el acceso a otros mundos mediante la televisión, el internet, son factores causales para un progresivo empoderamiento de las mujeres indígenas en distintos campos.

Como señalé antes, era una regla que todo hombre que ocupara un cargo debía estar casado o contar con el apoyo de su madre o hijas, que se tomaran a cuestas las tareas de la organización y preparación de los banquetes. De modo que las mujeres siempre han participado en posiciones adjuntas pero determinantes. Como apunta Rodríguez Blanco: los hombres se ocupan del cargo, mientras las mujeres se ocupan de la carga que implica el cargo (op. cit.: 93). Es importante pues subrayar que siempre ha sido imprescindible la presencia y trabajo de las mujeres para el buen desarrollo de las ceremonias y banquetes que implican las fiestas de mayordomía. Sin su participación no habría sido ni sería posible el desempeño ritual de sus cónyuges, familiares y vecinos a quienes apoyan en las tareas culinarias, en la coordinación del protocolo y en la organización del trabajo ceremonial.

Sin embargo, es inviable afirmar que en los pueblos de la sierra de Zongolica las mujeres hayan estado relegadas a los espacios privados en las fiestas de mayordomía, como señala la autora antes citada para Cuetzalan, Puebla. Las esposas, 
hijas y madres de los mayordomos asumen importantes roles ceremoniales en el espacio público y siempre han sido partícipes, si bien de forma menos explícita, del prestigio adquirido por estos. Como anfitrionas de las fiestas reciben la colaboración de familiares y vecinas que se dedican a las labores de la cocina mientras ellas atienden a los invitados y cumplen con el protocolo ceremonial. Asimismo, colaboran a su vez en las obligaciones rituales de otras familias, participando en un sistema de ayuda mutua, aportando su colaboración en especies y en tiempo de trabajo. Incluso continúa siendo usual la referencia en común -los mayordomos- a los titulares de las fiestas cuando se trata de una pareja de cónyuges.

La novedad ahora estriba en la posibilidad de poner en práctica otras formas de apropiación de los símbolos y esferas sagradas por parte de las mujeres que no conforman una pareja. Generalmente las mujeres con cónyuges migrantes se convierten en administradoras del patrimonio familiar y fungen como representantes del esposo en trámites y gestiones locales. Ellos controlan vía telefónica sus decisiones, entradas y salidas de casa, así como los usos que se dan a las remesas, aunque en ocasiones la ausencia del esposo permite avances en la autonomía femenina y en la posibilidad de desarrollar negocios propios y gestionar su tiempo libre y su movilidad en el espacio local. Pero como señalé líneas arriba, ellas solo tomarán un cargo de mayordomía hasta que el marido haya vuelto de su estancia en "el otro lado" para asumir juntos las obligaciones y tareas respectivas.

\section{Comentario final}

El estudio de la comunidad transnacional exige volver la mirada a las comunidades de origen, especialmente cuando nos interesamos en la reestructuración de los campos religiosos locales. En estas páginas traté de mostrar la relación entre la migración masculina hacia Estados Unidos y la transformación de las jerarquías de comisión establecidas para el culto a los santos, identificando el rol de las mujeres en este proceso. Según mis observaciones, en esta nueva organización de lo sagrado, las mujeres nahuas que permanecen en los lugares de origen, reproducen las fiestas patronales y otras celebraciones que permiten la resignificación de la idea de comunidad a pesar de la ausencia de familiares y vecinos.

El sistema de cargos religiosos se desarrollaba en el marco de la estructura patriarcal, pero la migración transnacional masculina ha dado lugar a la intervención de las mujeres en los puestos religiosos -e incluso civiles- de los cuales estaban excluidas. Ellas participan-adquieren nuevos estatus a partir de su función protagónica en las fiestas de mayordomía y de su independización en otras esferas de la vida diaria.

De este modo reproducen y resignifican el sistema de cargos religiosos en resiliencia a la desintegración familiar y comunitaria. Las motivaciones explícitas son de carácter devocional y religioso; manifiestan hacerlo "de corazón" y con mucha fe y devoción por los "santitos" del calendario ritual. Si bien estas motivaciones son incuestionables, opera también el peso de la ratificación social en su desempeño, utilizando los símbolos del prestigio masculino asociado a la jefatura del hogar y a la gestión en la escena pública. Como señala Rodríguez Blanco (op. cit.) en referencia a Cuetzalan, Puebla, en la sierra se valora positivamente la creciente participación de las mujeres en los cargos religiosos; los hombres no las censuran porque no compiten por ellos. Paralelamente, los ancianos, es decir, quienes han asumido los puestos de maryordomía más importantes a lo largo de su vida, han perdido espacios de poder y decisión tanto en la esfera religiosa como en la civil.

En coincidencia con lo señalado por De la Cadena (1992) los cambios en la valoración del trabajo -en los que el trabajo migratorio transnacional es más valorado que el trabajo agrícola- ocurren a la par de las transformaciones del sistema patriarcal y de los símbolos de estatus al interior de las comunidades. Dichos símbolos se han diversificado e incluyen ahora la posesión de casas de mampostería, autos y teléfonos celulares.

Queda pendiente la tarea de profundizar en los procesos actuales de cambio cultural que están incidiendo en el panorama religioso de la sierra, así como en los derroteros de las nuevas generaciones de hombres y mujeres indígenas. 


\section{Referencias Citadas}

Aguirre Beltrán, Gonzalo

1991 [1967] Regiones de Refugio. México, Fondo de Cultura Económica.

Aguirre Beltrán, Gonzalo 1986 Zongolica. Encuentro de dioses y santos patronos. Xalapa, Universidad Veracruzana.

Argyriadis, Kali; De La Torre, Renée; Gutiérrez Zúñiga, Cristina y Aguilar Ros, Alejandra (coords.)

2008 Raíces en Movimiento. Prácticas religiosas tradicionales en contextos translocales. México, El Colegio de Jalisco-CEMCA-IRD-CIESAS-ITESO.

Báez-Jorge, Félix 1998 Entre los naguales y los santos. Xalapa, Universidad Veracruzana.

Bauman, Zygmunt

2001 La Globalización. Consecuencias Humanas. México, Fondo de Cultura Económica.

Bricker, Victoria R.

1989 El Cristo Indígena, el Rey Nativo. México, Fondo de Cultura Económica.

Cámara, Fernando

[1952] 1996 "Organización Religiosa y Política en Mesoamérica", en: Leif Korsbaek, comp. Introducción al Sistema de Cargos. México, Universidad Autónoma del Estado de México, pp. 113-159.

Cancian, Frank

1976 Economía y Prestigio en una Comunidad Maya. México, Instituto Nacional Indigenista.

Cancian, Frank

1990 "The zinacantan cargo waiting lists as a reflection of political and economic changes. 1952 to 1987", en: Stephen y Dow, eds. Class, Politics, and Popular Religion in Mexico and Central America. Washington. Society for Latin American Anthropological Publication Series, Volume 10, pp. 63-76.

Cantón, Manuela

1998 Bautizados en fuego. Protestantes, discursos de conversión y política en Guatemala (1989-1993). La Antigua, Guatemala, CIRMA.

Clifford, James

1999 Itinerarios Transculturales. Barcelona, Ed. Gedisa.

Chance, John K.

1990 "Changes in Twentieth-Century Mesoamerican Cargo Systems", en: Stephen y Dow, eds. Class, Politics, and Popular Religion in Mexico and Central America. Washington. Society for Latin American Anthropological Publication Series, Volume 10, pp. 27-42.

Chance, John y B. Taylor, William

1987 "Cofradías y cargos: una perspectiva histórica de la jerarquía cívico-religiosa mesoamericana”, en: Antropología suplemento. Boletín oficial del INAH. México, Nueva Época, Núm 14.

D’Aubeterre, María Eugenia

2005 "San Miguel Arcángel, un santo andariego. Trabajo ceremonial en una comunidad de transmigrantes del estado de Puebla". En: Relaciones, El Colegio de Michoacán, No 103, Vol. XXVI, pp. 19-50.

De la Cadena, Marisol

1992 "Las mujeres son más indias: Etnicidad y género en una comunidad del Cuzco", en: Revista Isis Internacional, Santiago de Chile, Ediciones de las Mujeres, No 16, pp. 25-46.
Dow, James W.

1993 "Protestantismo en el campo: causas materiales del abandono de fiestas en la Sierra Oriente de Hidalgo", en: Notas Mesoamericanas, México, Universidad de las Américas-Puebla, No 14, pp. 123-130.

Durand, Jorge y Massey, Douglas

1995 Miracles on the Border: Retablos of mexican migrants to the Unites States. The University of Arizona Press.

Garma, Carlos

1987 Protestantismo en una comunidad totonaca de Puebla, México. México, Instituto Nacional Indigenista.

Garma, Carlos

1998 "Afiliación religiosa en municipios indígenas de Chiapas según el censo de 1990". En: Chiapas: el factor religioso. Publicaciones para el Estudio Científico de las Religiones. México, pp. 189-216.

Garma, Carlos

2004 Buscando el espíritu. Pentecostalismo en Iztapalapa y la ciudad de México. México, UAM-Iztapalapa/Plaza y Valdez.

Hernández Madrid, Miguel

2003 "Diversificación religiosa y migración en Michoacán". En: Diáspora Michoacana. Zamora, El Colegio de Michoacán, pp. 165-192.

Hernández, Alberto y Garma, Carlos

2007 "Los rostros étnicos de las adscripciones religiosas". En: Atlas de la Diversidad Religiosa en México (1950-2000) (Renée de la Torre y Cristina Gutiérrez Zúñiga, coords.). México, CIESAS-COLEF-Secretaría de Gobernación-COLMICH.

Hirai, Shinji

2009 Economía Política de la Nostalgia. Un estudio sobre la transformación del paisaje urbano en la migración transnacional entre México y Estados Unidos. México, UAM-Juan Pablos Editor.

Korsbaek, Leif

1996 Introducción al Sistema de Cargos. México, Universidad Autónoma del Estado de México.

Levitt, Peggy y Glick-Schiller, Nina

2004 "Conceptualizing Simultaneity: A Transnational Social Field Perspective on Society. En: International Migration Review. No 38, pp. 1002-1039.

López Austin, Alfredo

1994 Tamoanchan y Tlalocan. México, Fondo de Cultura Económica.

Long, Norman

2007 Sociología del desarrollo: una perspectiva centrada en el actor. México, CIESAS-Colegio de San Luis.

Macip, Ricardo Francisco

2005 Semos un país de peones: café, crisis y el estado neoliberal en el centro de Veracruz. Benemérita Universidad Autónoma de Puebla.

Martínez Canales, Luis Alejandro

2010 Tlen Yawi Ne Wehka: Cultura, Trabajo y Conciencia de los Migrantes Nahuas de la Sierra de Zongolica, Veracruz. México, UNAM-IIA, Tesis de doctorado en Antropología.

Morán, Luis Rodolfo

2000 Representación religiosa de los mexicanos exiliados. Guadalajara, El Colegio de Jalisco-Universidad de Guadalajara. 
Odgers, Olga y Ruiz, J. Carlos (coords.)

2009 Migración y Creencias., Pensar las religiones en tiempos de movilidad. México, El Colegio de la Frontera Norte-El Colegio de San Luis-Miguel Ángel Porrúa.

Odgers, Olga

2014 "Migración y cambio religioso en México: perspectivas de análisis y agenda de investigación”. En: Cultura y Religión. Universidad Arturo Prat del Estado de Chile, Vol. VIII, No 1 , enero-junio 2014, pp. 151-167.

Rivera Sánchez, Liliana

2004 "Transformaciones comunitarias y remesas socioculturales de los migrantes mixtecos poblanos". En: Migración y Desarrollo, Vol. 2, pp. 62-103.

Rivera, Carolina

1998 "La diáspora religiosa en Chiapas, notas para su estudio". En: Chiapas: el factor religioso. Publicaciones para el Estudio Científico de las Religiones. México, pp. 173-188.

Rivera, Carolina y Juárez Cerdi, Elizabeth (eds.)

2010 Más allá del espíritu. Actores, acciones y prácticas en iglesias pentecostales. México, CIESAS.

Robledo, Gabriela

1997 Disidencia y religión. Los expulsados de San Juan Chamula. Tuxtla Gutiérrez, Chiapas. Colección de Ciencias Sociales, Serie Migración y Religión, $\mathrm{N}^{\circ} 2$, UNACH.

Robledo, Gabriela

1998 Betania y Nuevo Zincantán. La recomposición de dos comunidades tzotziles en los Altos de Teopisca, Chiapas. Tesis de Maestría en Antropología Social. México, ENAH.

Rodríguez Blanco, Eugenia

2011 "Género, etnicidad y cambio cultural: feminización del sistema de cargos en Cuetzalan". En: Política y Cultura. México, UAM-Xochimilco, Núm. 35, pp. 87-110.

Rodríguez, María Teresa

2003 Ritual, Identidad y Procesos Étnicos en la Sierra de Zongolica, Veracruz. México, CIESAS.

Rodríguez, María Teresa

2009 "Mayordomías y nuevas prácticas religiosas. Espacio, religión y política en comunidades nahuas". En: Pensamiento religioso y espacio de poder (Báez-Jorge, Félix, Rogelio de la Mora, Guadalupe Vargas y José Velasco Toro, coords.), Editora de Gobierno del Estado de Veracruz, pp. 61-92.

Rodríguez, María Teresa

2011 "Nahuas en Wisconsin: movilidad, localidad y participación religiosa”. En: Nuevos caminos de la fe. Prácticas y creencias al margen institucional. México, COLEF, COLMICH, UANL, pp. 323-344.

Rodríguez, María Teresa

2012 "Itinerarios transnacionales de comunidades nahuas hacia los Estados Unidos". En: En sentido contrario. Transnacionalización de religiones africanas y latinoamericanas (Kali Argyriadis, Stefania Capone, Renée de la Torre y André Mary, coords.). México, CIESAS, pp. 885-95.

Rodríguez, María Teresa

2013 "Una aproximación al proceso de diversificación religiosa en un municipio nahua". En: Alteridades, México, UAM-Iztapalapa, pp. 25-35.

Rodríguez, María Teresa

2014 "Repertorios culturales, formas de sustento y dinámicas familiares entre jóvenes nahuas migrantes", en: Juventudes en Frontera. Tránsitos, procesos y emergencias juveniles en México, Chile, Nicaragua y Argentina (Tania Cruz Salazar y Yanko González, eds.). Quito, Ed. Abya - Yala/ El Colegio de la Frontera Sur, pp. 57-84.

Sassen, Saskia

2012 Una sociología de la globalización. Buenos Aires, Katz Ed.

Tax, Sol

[1937] 1996 "Los Municipios del Altiplano Mesooccidental de Guatemala", en: Introducción al Sistema de Cargos, (Leif Korsbaek, comp.), México, Universidad Autónoma del Estado de México, pp. 87-112.

Wasserstrom, Robert

1989 Clase y Sociedad en el Centro de Chiapas. México, Fondo de Cultura Económica.

Wolf, Eric

[1967] 1986 Pueblos y Culturas de Mesoamérica. México, Ed Era.

\section{Notas}

1 Estas reflexiones se basan en observaciones y entrevistas realizadas en distintas localidades de los municipios mencionados, en diferentes temporadas a lo largo de varios años (del 2009 al 2013). También llevé a cabo varias entrevistas a migrantes varones, procedentes de estos municipios, en una de las zonas de recepción de migrantes nahuas en Estados Unidos, las granjas lecheras del estado de Wisconsin, así como a migrantes de retorno en sus comunidades de origen.

2 La sierra de Zongolica - ubicada en la franja central del estado de Veracruz, en la cordillera este de la Sierra Madre Oriental-se integra por trece municipios cuya población es mayoritariamente hablante del náhuatl como primera lengua. El espacio físico de la sierra se compone de una diversidad de ecosistemas ubicados entre los 500 y los 2.500 metros sobre el nivel del mar. Los municipios de la zona fría han sido considerados de alta marginalidad debido a la escasez de fuentes de empleo, al extremo minifundismo y a la pobreza de los suelos. Como en otros contextos rurales e indígenas de nuestro país, en la última década se han acentuado en esta zona los procesos migratorios hacia fuera del espacio regional y nacional.

3 La convivencia entre las diferentes propuestas religiosas, en determinados contextos serranos, ha sido fuente de conflictos y confrontaciones graves e incluso violentas (cfr. Rodríguez, 2013).

4 María Eugenia D'Aubeterre (2005) propone la noción de conyugalidad a distancia, para referirse a la experiencia de la vida marital asociada a la migración masculina en hogares multisituados y a la jefatura femenina de facto, incluyendo las maneras en que las mujeres apuntalan los bienes simbólicos.

5 Es preciso apuntar que existe también un proceso migratorio aún incipiente de mujeres jóvenes que se aventuran a cruzar la frontera para conseguir trabajo en diferentes lugares de la Unión Americana. 
6 Glick-Schiller, Bash y Blanc-Szanton (1992) propusieron el término transnacionalismo para definir la conformación de un espacio social caracterizado por vínculos sociales que conectan a los que se desplazan y a los que se quedan en una estructura intangible de densas redes de relación entre dos o más países. Quienes se quedan de este lado de la frontera, si bien no se desplazan físicamente, viven su vida en un contexto transnacional debido al contacto frecuente con sus familiares, al envío de remesas y a las circulaciones culturales de uno y otro lado de la frontera. 
